Espaço Aberto | Open Space

\title{
Argonautas, cem anos: uma releitura em pesquisas do Núcleo de Antropologia Urbana da USP
}

\begin{abstract}
A hundred years of Argonauts: a reinterpretation based on USP's Urban Anthropology Center research
\end{abstract}

José Guilherme Cantor Magnani'

https://orcid.org/0000-0002-5263-1459

jmagnani@usp.br

I Universidade de São Paulo - São Paulo, SP, Brasil 


\title{
Resumo
}

O centenário da publicação de Argonautas do Pacífico Ocidental enseja não apenas a necessária referência, mas um cuidadoso resgate da contribuição para a prática etnográfica e reflexão conceitual que a saga de Bronislaw Malinowski legou para a antropologia. Claro, é necessária uma também cuidadosa releitura de seus achados nas Ilhas Trobriand tendo em vista a realidade atual, principalmente quando os temas de pesquisa têm como recorte a dinâmica das grandes cidades contemporâneas. Essa é a linha que percorre o presente artigo, com base em pesquisas e experimentos no âmbito da antropologia urbana, levados a cabo por integrantes do Laboratório do Núcleo de Antropologia Urbana da USP (LabNAU).

Palavras-chave: Argonautas do Pacífico Ocidental; Bronislaw Malinowski; antropologia urbana; LabNAU/USP.

\begin{abstract}
The centennial of the Argonauts of the Western Pacific entails not only a necessary reference, but a thorough recovery of its contribution both to the ethnographic practice and the conceptual reflexion that Malinowski saga conveyed to Anthropology. Surely, a careful rereading of his findings in the Trobriand Islands is also necessary, regarding the contemporary reality, particularly when the research topics frame the contemporary great cities' dynamics. This is the thread going through the present article, based on researches and experiments in the scope of Urban Anthropology, carried out by members of the Nucleus of Urban Anthropology Lab of the University of São Paulo (LabNAU/USP).
\end{abstract}

Keywords: Argonauts of the Western Pacific; Bronislaw Malinowski; urban anthropology; LabNAU/USP. 


\section{Introdução}

Imprescindível e desafiador: um texto sobre o legado de Bronislaw Malinowski em comemoração aos cem anos da publicação de Argonautas do Pacífico ocidental (Malinowski, 1922), além de necessário, implica desafios: só as citações bibliográficas com os artigos, resenhas, livros, teses, análises e críticas sobre sua obra certamente preencheriam as páginas dedicadas ao artigo solicitado. E como seria a introdução? Começar pelo famoso parágrafo inicial desse livro?

Imagine-se o leitor sozinho, rodeado apenas de seu equipamento, numa praia tropical próxima a uma aldeia nativa, vendo a lancha ou o barco que o trouxe afastar-se no mar até desaparecer de vista [...] nada tem a fazer a não ser iniciar imediatamente seu trabalho etnográfico. (Malinowski, 1978, p. 19).

Que estudante de ciências sociais já não o conhece? Ou então uma respeitosa referência aos achados - o kula e a observação participante; o passeio diário pela aldeia e o caderno de campo, o aprendizado da língua e os quadros sinóticos... E que dizer dos decantados "deslizes" posteriores às monografias: a "teoria científica da cultura" e o diário íntimo, em polonês, com todas aquelas expressões depreciativas... ${ }^{1}$ Evidentemente não é o caso de seguir uma certa tendência de ajuste de contas, na esteira da recente queima de monumentos de personagens, hoje lidos na chave de uma polêmica postura do "politicamente correto", nem de alguma forma de "cancelamento", tão em voga na atual conjuntura...

Temas não faltam, pois; o desafio, então, para fugir aos lugares-comuns, será encontrar um fio condutor que leve em conta o legado (e as ressalvas), reconheça sua permanência, mas suscite novas abordagens. Essa será a alternativa escolhida para participar, com este texto, na seção Espaço Aberto do número de Horizontes Antropológicos, dedicada ao centenário de Argonautas.

Todos os que vieram depois da celebrada saga no arquipélago de Trobriand, costa oriental da Nova Guiné - os modernos, os pós-modernos, os simétricos, os reversos, os da virada ontológica e da metodológica, os antropocenistas,

1 Vejam-se, a propósito, a segunda introdução, de 1988, de Raymond Firth, respondendo a algumas dessas críticas ao diário (Malinowski, 1989, p. xxi) e a introdução de Eunice Durham (1978a, p. xxiii-xxiv) à edição brasileira de Argonautas. 
os "que estiveram lá" e os que não estiveram - em suas diferentes épocas e contextos, de uma forma ou outra, direta ou indiretamente, lhe devem crédito. Também já é sobejamente estabelecido que não foi Bronislaw Malinowski quem iniciou a pesquisa de campo com a aplicação do que posteriormente ficou denominado como "observação participante": antes dele Franz Boas (1922) e Robert Lowie (1954) e as incursões a populações indígenas das planícies nos EUA; A. R. Radcliffe-Brown (1922) nas Ilhas Andaman; C. G. Seligman (1910) e William H. R. Rivers (1906) na famosa expedição ao Estreito de Torres (18881889) e outros mais intentaram pesquisas em novos moldes, em contraposição à antropologia "de gabinete", "de convés" ou "de varanda". ${ }^{2}$

No entanto, é em Argonautas que a preocupação com a metodologia, seguindo um protocolo - portanto, capaz de ser replicado em outras situações e por outros antropólogos, teve sua sistematização. Além disso, sua escrita, principalmente nas monografias, comparada, por alguns autores, ao do conterrâneo Joseph Conrad (1984), em o Coração das trevas, marcou um estilo que até mereceu por parte de James Clifford (1998, p. 27), citando artigo de Thornton (1983), uma definição: "descrição cultural sintética baseada na observação participante".

Feitas essas considerações preliminares, cabe agora apresentar a linha que será seguida na continuação, e o ponto central será desenvolvido a partir de alguns relatos de experimentações feitas em diferentes contextos, por parte de pesquisadores do Laboratório do Núcleo de Antropologia Urbana da USP (LabNAU), tendo como referência recomendações metodológicas sugeridas em Argonautas. Em poucas palavras, trata-se de uma mudança de protocolo: do olhar de um pesquisador individual para os olhares de integrantes de uma equipe, com distinções do marcador de gênero, idade, formação, entre outros; de uma estada em campo prolongada e contínua para a imersão, em tempo mais reduzido e com volta diária para casa; das anotações do diário de campo pessoal para o compartilhamento das observações - transcritas das anotações do caderno para a forma de relatos que servirão para enriquecer o olhar de cada um(a) e os do(a)s colegas, nos dias subsequentes.

2 Cabe uma nota sobre a influência da publicação The native tribes of Central Australia, resultado de pioneira pesquisa de Spencer e Guillen (1899), que terminou influenciado obras como Totem e tabu de Sigmund Freud (1913); Formas elementares da vida religiosa: o sistema totêmico na Austrália, de Émile Durkheim (1912), e do próprio Malinowski (1913), A família entre os aborígenes australianos, antes de sua famosa viagem à costa oriental da Nova Guiné. 


\section{Etnografia compartilhada: uma trajetória}

Esse processo, que será detalhado a seguir - como foi desenvolvido e aplicado ao longo das pesquisas no LabNAU - exigirá uma volta no tempo para apreciar as tentativas até se chegar à formulação sintética acima referida. Vou privilegiar um começo caseiro: não posso deixar de mencionar, logo de início, a contribuição de Eunice Durham, minha professora no Programa de Pós-Graduação em Antropologia Social da USP.

Tendo regressado de um período no exterior, com mestrado concluído na Facultad Latinoamericana de Ciencias Sociales (FLACSO-Chile) e depois de um tempo com pesquisa em Buenos Aires, após o golpe que depôs Salvador Allende, já de volta ao Brasil em 1978, fui aprovado no PPGAS da USP para o doutorado. Minha orientadora foi a professora Ruth Cardoso, que juntamente com Eunice Durham consolidaram o tema da antropologia urbana no Departamento de Antropologia da FFLCH da USP.

Minha tese foi sobre uma forma de lazer e entretenimento popular em bairros da periferia, o circo-teatro (defendida em 1982), e durante o curso, juntamente com minhas colegas Alba Zaluar, Teresa Caldeira, Carmen Cinira, Paula Montero, Guita Grin, Ana Maria Niemeyer e outro(a)s mais, ${ }^{3}$ compartilhávamos das reuniões das segundas-feiras sob orientação de Ruth e Eunice: as discussões tinham como referência autores como Antonio Gramsci, Louis Althusser, Manuel Castells, Nicos Poulantzas, Richard Hoggart, não contemplados na literatura habitual dos clássicos da antropologia. Mas Malinowski se fazia presente no meio dessa turma, pois, já em 1973, Eunice havia defendido sua livre-docência, publicada em 1978 sob o título A reconstituição da realidade, e que assim começava:

O caráter polêmico, complexo e contraditório da obra de Bronislaw Malinowski constitui uma manifestação da vitalidade de seu pensamento e uma expressão de sua própria carreira. Este polonês que se tornou um dos grandes antropólogos britânicos, professor brilhante que influiu profundamente em toda uma geração

3 Em Da periferia ao centro: trajetórias de pesquisa em antropologia urbana Magnani (2012) está a lista com todos os orientandos: foram 25 com Eunice e 34 com Ruth; aí também detalho esse processo da "descoberta da periferia". 
de antropólogos ingleses, foi sempre alvo de admiração e de críticas violentas. (Durham, 1978b, p. 7).

O NAU, de certa forma, deu continuidade à tradição dos seminários das segundas-feiras. Quando comecei a ter alunos de pós-graduação, já como professor no Departamento de Antropologia da FFLCH da USP, para escapar da relação demasiadamente individual orientador/orientandos, propus esse núcleo para compartilhar bibliografia, experiências de campo, dúvidas. De lá para cá foram 58 defesas de dissertações, teses e pós-doutorados, sem contar trabalhos de iniciação científica por mim orientados na graduação. Recentemente foi acrescentado o termo "laboratório" - LabNAU - pois a cidade de São Paulo foi o principal espaço de experimentação por meio da família de categorias: pedaço, trajeto, mancha, circuito, pórtico, para estudar a dinâmica da cidade, de "perto e de dentro". 4

Contudo, outras cidades de menor escala foram contempladas, inclusive algumas na Amazônia. Atualmente, a equipe dos "Argonautas - Pesquisa Enográfica”, formada por ex-alunos (também membros do NAU) e já no mercado de trabalho, acolhem demandas para além da academia, mas com o protocolo desenvolvido com base em pesquisas, textos e experiências teórico-metodológicas da disciplina. ${ }^{5}$

A seguir, algumas etapas da trajetória que têm a ver mais especificamente com o desenvolvimento de escolhas etnográficas que remetem aos achados da obra de Malinowski. Antes, porém, faz-se necessário explicitar uma dessas escolhas, a que terminou sendo denominada de "etnografia compartilhada". Trata-se de uma das adaptações do legado malinowskiano às condições atuais da pesquisa, mormente em contextos urbanos e globalizados do mundo contemporâneo. George Marcus (2001) cunhou a expressão "etnografia multissituada", para referir-se a uma dessas adaptações em que o foco do interesse se desloca de um recorte localmente delimitado e se amplia para dimensões mais

4 No artigo “Etnografia como prática e experiência” (Magnani, 2009) faço referência a esse conceito e a essas categorias.

5 São eles: Enrico Spaggiari, Mariana Hangai, Rodrigo Chiquetto, Yuri Bassichetto; faço parte do grupo como orientador. 
abrangentes e/ou geográficas não contíguas, no quadro do "sistema mundo", como afirma. Interessante notar que, entre os inúmeros autores contemporâneos que cita e, mais concretamente, ao referir-se a uma das características da etnografia multissituada - seguir as pessoas -, de repente, en passant, aparece Malinowski: "Esta técnica é provavelmente a maneira más obvia e convencional de materializar uma etnografia multissituada. Argonautas do Pacífico Ocidental é o livro arquetípico" (Marcus, 2001, p. 118, tradução minha).

No caso da "etnografia compartilhada", contudo, tanto a referência como a ressalva com respeito às recomendações malinowskianas são outras. Aqui, não é a questão da ampliação ou multiplicação dos recortes - ainda que possam também ocorrer -, mas a troca de informações colhidas pelos integrantes de uma equipe. Tampouco é apenas uma ida coletiva a campo ou convivência social entre os pesquisadores, mas um compartilhamento sistemático dos dados colhidos individualmente; não é, contudo, o caderno de campo que circula, mas já uma primeira elaboração, o relato de campo, em que os dados, às vezes apenas rabiscados, são passados a limpo; o caderno, porém, continua sendo de manuseio pessoal. Esse compartilhamento permite que, na próxima incursão, cada pesquisador possa matizar seu olhar com as nuances dos de seus colegas - marcados por gênero, formação, idade, gostos, etc. de cada um. Essa estratégia permite, ademais, minimizar o aspecto subjetivo que muitas vezes é atribuído ao método etnográfico, quando comparado às (supostamente) objetivas ferramentas de registro como questionários, entrevistas estruturadas, etc. Evidentemente essa estratégia, no caso do LabNAU, foi sendo elaborada aos poucos; as primeiras experiências de campo não a tinham sistematizado, como se verá a seguir.

\section{Expedição São Paulo}

Em outubro de 1985, participei de uma original iniciativa do arquiteto Júlio Abe Wakahara, "Expedição São Paulo: refazendo os antigos caminhos de São Paulo", patrocinada pelo Jornal da Tarde e pelo Centro Cultural São Paulo da Secretaria Municipal de Cultura. Foi uma expedição que durou sete dias, atravessando a cidade de ponta a ponta. Doze especialistas - das áreas das ciências ambientais, arquitetura, urbanismo, antropologia, sociologia, história -, seguidos de perto por jornalistas e fotógrafos, percorreram uma rota inspirada 
nos percursos dos viajantes do século XIX. As perguntas eram: como seria São Paulo aproximadamente cem anos depois dessas primeiras viagens? Que havia naquele espaço? Qual era sua população, onde morava, de que se ocupava, onde e como se divertia, que problemas enfrentava?

No decorrer dessa semana foram feitas visitas, entrevistas e observações, tudo devidamente registrado, dia a dia, pelo jornal. A "Expedição São Paulo" inspirava-se na saga dos antigos viajantes, mas as modalidades de registro e comunicação, contudo, constituíram uma inovação. A ideia era experimentar um novo veículo museológico: ágil, direto, seguindo o formato do meio escolhido, o jornal diário. O primeiro contraste, que, aliás, esteve na origem da proposta, foi sugerido pela comparação entre duas imagens: uma, que retratava o quase vazio da paisagem oitocentista; a outra - emaranhada, densa -, captada por meio de uma tecnologia então inovadora, a câmera do satélite Landsat. Era já impressionante a mancha urbana de São Paulo, destacando-se na paisagem: aliás, só mesmo do alto do satélite teria sido possível abarcar suas dimensões e visualizar suas bordas. O desafio, então, foi atravessar essa mancha, aqui de baixo.

Não se tratava de trabalho de cunho jornalístico nem, evidentemente, de uma pesquisa etnográfica stricto sensu. O propósito era deixar-se impregnar pelas sensações produzidas pelas múltiplas vozes, sons, cheiros, cores, espaços, edificações e o próprio ritmo da metrópole, cuidando para que essa avalanche fosse filtrada pelo olhar de cada especialista e compartilhada entre nós. Assim, em vez de conceitos, análises exaustivas ou interpretações complexas, o que se produziu foi um conjunto de relatos, entremeados de insights e metáforas. O desafio era articular todos esses relatos sobre a dinâmica e o espaço urbano - tomando a cidade em seu conjunto, no decurso de uma semana e no transcorrer de uma caminhada contínua - com base no compartilhamento de impressões entre os viajantes em seu convívio diário.

\section{Expedição São Paulo 450 anos}

A experiência de 1985 serviu de inspiração, estímulo e contraponto para reeditá-la quase 20 anos depois e em função de uma data muito especial: a celebração dos 450 anos de fundação de São Paulo, em 2004. A iniciativa foi resultado de uma parceria entre a Secretaria Municipal de Cultura, o grupo 
O Estado de São Paulo e o Instituto Florestan Fernandes; contou com o patrocínio da Petrobras e da Expomus/Exposições Museus Projetos Culturais Ltda. ${ }^{6}$

Assim, a "Expedição São Paulo 450 anos: uma viagem por dentro da metrópole" consistiu nas caminhadas de duas equipes compostas por 31 especialistas das áreas de antropologia, museologia, arqueologia, arquitetura e urbanismo, história, etnomusicologia, geografia, sociologia, artes, ciências ambientais, educação e psiquiatria, que percorreram a cidade de São Paulo, em uma semana, de ponta a ponta, uma no sentido sul-norte e outra, no leste-oeste, a partir de roteiros previamente estabelecidos. Para tanto foram decisivos os documentos e as fontes de informação produzidos em diversas instâncias da administração municipal, disponibilizados pelo Instituto Florestan Fernandes, que, ademais, viabilizou contatos com agentes locais e representantes de associações e movimentos sociais.

As equipes foram acompanhadas por estagiários - encarregados de fazer o registro da expedição - e profissionais de comunicação (jornal, rádio e internet), para transmissão das impressões colhidas durante todo o percurso sobre a cidade a respeito de seus habitantes, trajetos habituais, locais de moradia e sociabilidade, trabalho e lazer e as incontáveis, inesperadas e criativas respostas às condições concretas de vida nessa cidade.

Nesse caso, o experimento consistiu em organizar e realizar uma expedição que, também sem ser estritamente etnográfica, propiciou o contato direto entre especialistas de diferentes áreas do conhecimento e atores sociais em seus contextos de vida, num período curto e com roteiro estabelecido, instando os pesquisadores a confrontar seus quadros interpretativos com os pontos de vista dos moradores.

Entre os inúmeros e surpreendentes encontros, registro um: com Claudia Sofia, surdo-cega, que concedeu uma entrevista a Maria Ignez Mantovani, de uma forma que nenhum dos expedicionários conhecia: também desprovida de visão, ela não podia comunicar-se por meio de Libras, então se valia de Tadoma, um método que consiste em tocar o rosto do interlocutor com o polegar

6 Essa iniciativa, da qual fui coorganizador, contou com a participação dos professores Vagner Gonçalves, Luiz Henrique de Toledo e Maria Lúcia Montes, do Departamento de Antropologia da FFLCH da USP, e dos alunos, então membros do NAU, Camila Iwasaki, Clara Azevedo, Márcio Macedo, Alexandre Barbosa e Daniela do Amaral Alfonsi. 
de maneira a sentir o movimento da comissura dos lábios enquanto a outra mão acompanha a vibração das cordas vocais e assim se decodifica sua fala.?

Não se tratava, contudo, de um descomprometido mergulho na fragmentação de faits divers, mas uma imersão na diversidade a partir da qual, nas discussões noite após noite, o olhar de cada especialista suscitava questões e relativizava o dos demais: se para alguns o ruído urbano era uma mistureba indiscriminada e causava incômodo, o etnomusicólogo distinguia diversos "sons da cidade"; o arquiteto via soluções inusitadas em construções populares enquanto o restante dos expedicionários via ali apenas a precariedade, e assim por diante. O mote "de perto e de dentro", mesmo que não ainda formulado nesses termos, dava um tom etnográfico à experiência, principalmente a partir do compartilhamento das visões, escutas e sensações.

O propósito da expedição era justamente servir de antena para captar sinais, rastrear indícios, identificar aqui e acolá pistas muitas vezes só reconhecidas pelos próprios protagonistas, nos limites de seu cotidiano. Evidentemente não seria preciso nenhuma expedição desse porte para comprovar o quadro estrutural em seu contorno mais abrangente e identificar os fatores explicativos e indicadores de ordem macrossociológica e econômica.

Mas, quando se propôs essa "viagem por dentro da metrópole", o que se pretendia era ir além dessas alternativas, não para provar alguma tese ou buscar a comprovação de questões até já sabidas, mas para dispor-se a reconhecer outro horizonte e perceber a palpável e efetiva existência de redes sociais, iniciativas localizadas, arranjos coletivos, sistemas de trocas, projetos em parcerias, pontos de encontro, formas de autoproteção, de representação, de associação - sem os quais a vida social, nas suas múltiplas dimensões, já há muito estaria impossibilitada, no cenário dessa megalópole.

Tal era o objetivo da Expedição São Paulo nessa nova versão; ela tinha a seu favor a memória da anterior, da qual manteve o caráter experimental, lúdico, de exercício e de compartilhamento entre os excursionistas. O princípio mais geral que iria nortear o olhar era uma orientação afirmativa sobre a cidade e seus moradores. A conhecida "dura realidade" que se manifesta de forma mais

7 O método foi desenvolvido pela professora de duas crianças, Tad e Omã, que ficaram surdo-cegas como consequência da síndrome de Usher, surdez que se manifesta no início da vida, seguida ou não de perda visual que ocorre em idade mais avançada (Magnani et al., 2004, p. 142, nota 1). 
evidente no crescimento da violência, nas carências urbanas, nos índices de exclusão, etc. estaria sem dúvida em pauta, mas não para se repisar o que já é sabido. $\mathrm{O}$ que se queria flagrar eram as respostas criativas, imprevistas e pouco divulgadas da população a esse quadro, no horizonte do seu cotidiano.

Subprodutos desse trabalho foram o livro Expedição São Paulo 450 anos: uma viagem por dentro da metrópole (Magnani et al., 2004), o documentário de mesmo nome em DVD sobre a expedição (Expedição..., 2004), além de um CD-ROM e da exposição "Expedição São Paulo 450 anos", realizada na Galeria Olido, de dezembro de 2004 a janeiro de 2005. A intenção era replicar a expedição, de tempos em tempos, para captar as mudanças na dinâmica da cidade; com as mudanças políticas que se sucederam, porém, a iniciativa não teve continuidade.

\section{EtnOcupação}

O movimento estudantil que resultou na ocupação da reitoria da Universidade de São Paulo, no início de maio de 2007, já entrava em sua segunda semana quando me ocorreu propor aos estudantes do primeiro ano de Ciências Sociais, alunos da disciplina obrigatória "Introdução à Antropologia", que eu ministrava, fazer uma "etnografia da ocupação". A iniciativa foi recebida por alguns deles, ativamente engajados no movimento, como uma "atividade de greve", portanto legítima naquele contexto; outros a encararam como um motivo para continuar frequentando o campus, enquanto a maior parcela a tomou como uma oportunidade de fazer um exercício prático na área de antropologia, ainda que com poucas informações sobre a matéria, pois eram passados apenas dois meses do início das aulas quando se deu a paralisação. Apenas tinham iniciado o contato com a obra de Malinowski...

Quaisquer que tenham sido os motivos da aceitação da proposta, entretanto, rapidamente a notícia correu e em torno de 30 a 40 alunos (das três turmas e dos dois períodos) se interessaram, batizando a iniciativa de "EtnOcupação". Logo se constituiu uma comunidade no Orkut, começaram as observações com cadernos de campo, câmeras digitais e gravadores em punho: dessa forma, novos personagens (alguns já eram ocupantes) passaram a frequentar o prédio e as imediações.

Não será possível detalhar aqui todo esse processo de aplicação dos primeiros conhecimentos adquiridos em sala de aula diante de uma situação 
que transcendeu em muito o contexto da USP e gerou grande polêmica. Foi particularmente estimulante vê-los experimentar a postura etnográfica em contraponto com as distintas posições em disputa - de partidos políticos, da imprensa, da reitoria, do governo do estado, de grupos de professores e de alunos contrários ao movimento, além de muitos outros atores envolvidos.

É apropriado o uso do termo "experimentar", tanto por parte dos etnógrafos como dos atores envolvidos: o experimento destes suscitava naqueles um olhar mais atento, dado o ineditismo de ambos. Gosto de citar, a quem pergunta sobre a natureza de tais "experimentos", a observação do caderno de campo de uma das jovens etnógrafas que registrou o surgimento de uma nova regra certamente teria passado despercebido a um olhar não treinado, ou visto como mero detalhe: $\mathrm{o}$ uso de pratos e talheres que, em algumas circunstâncias, eram passados sem lavar, ao próximo da fila - do contrário esta não andava. A justificativa era de que "a mesma comida não suja": digno de Mary Douglas!

Acompanhei a experiência discutindo questões éticas, pontuando temas, sugerindo alguma bibliografia para discussão e, principalmente, propondo uma estratégia para direcionar a pesquisa de campo, com base no protocolo: descrever o cenário, identificar os atores e desvendar as regras. Simples assim, e, para registrar as observações, o "velho e bom caderno de campo" (Magnani, 1977). Foram 26 dias de ocupação, com imersão em campo: preparação de refeições, dormitório comum, limpeza e assembleias madrugada adentro.

Simples é modo de dizer, pois foi preciso estabelecer contato com os ocupantes, explicar os motivos, vencer resistências; depois, organizar as idas a campo, fazer observação participante, passar a limpo as anotações, seguir a repercussão na mídia, acompanhar as assembleias, identificar as siglas de partidos e movimentos. O cenário se ampliava (incluía as passeatas), os atores se multiplicavam - já não eram apenas alunos e funcionários, ou a favor e contra - e as regras, bem, havia as explícitas e as implícitas... Ou seja, o fato começou a aparecer em toda sua complexidade, resistente a leituras parciais, apressadas. Pena que o conceito de "fato social total" de Marcel Mauss só seria estudado após a retomada das aulas...

Essas foram as primeiras experiências de uma etnografia compartilhada. Pode partir do senso comum, das posições fechadas no calor das disputas, mas, ao acompanhar de "perto e dentro" e levar a sério os atores, permite perceber lógicas de ações e comportamento supostamente já conhecidos. Cadernos de 
campo, relatos, relatório final - tudo de acordo com o protocolo; só não saiu a publicação... ${ }^{8}$

\section{Experiências na Amazônia}

No início de 2009, a convite da professora Marta Amoroso do PPGAS da USP, o NAU foi convidado para participar do projeto "Paisagens ameríndias: habilidade, mobilidade e sociabilidade nos rios e cidades da Amazônia" (Procad/ Capes). Outro desafio, pois não tínhamos nenhuma experiência direta no campo clássico da etnologia, mas esse tipo de convite não se recusa, dado o ineditismo da proposta: registar a presença indígena em cidades da Amazônia, suas formas de sociabilidade - incluindo lazer e práticas de uso do "tempo livre", tema que o NAU encarava, há algum tempo, mas no contexto paulistano.

Uma equipe formada por Ana Fiori, Ana Sertã, Rodrigo Chiquetto, Yuri Bassicheto e José Agnello foi para lá, munida das categorias pedaço, trajeto, mancha, pórtico, circuito para um experimento em novo cenário, aldeias urbanas em Manaus e em cidades médias da região e com novos atores, os Sateré-Mawé no Baixo Amazonas: que regras organizavam suas formas de mobilidade, apropriação e uso da cidade? O trabalho, que durou três anos, mas de forma intermitente, com idas e vindas, permitiu ao NAU pôr à prova e estender o alcance dessas categorias, surgidas e desenvolvidas no contexto da metrópole. ${ }^{9}$

Se comparado com a expedição de Malinowski foi até um período longo. Uma de suas notas distintivas, o compartilhamento entre os pesquisadores, revelou-se fundamental, tendo em vista os temas que foram surgindo: a presença dos indígenas num torneio estadual de futebol amador, o artesanato das mulheres na Associação das Mulheres Sateré-Mawé (AMISM), que lhes permitia percorrer e reconhecer Manaus, a presença de jovens indígenas nas universidades, a repercussão da festa da Tucandeira (rito de passagem), o papel das mulheres como desbravadoras nas primeiras incursões à cidade com suas

8 O relatório foi assinado por Alvaro Kanasiro, Breno Barlach, Carolina Scheidecker, Flávia Belletati, Leticia Shimoda, Marina Cerchiaro, Rafael Mucinhato, Rodrigo Chiquetto, Yuri Tambucci (ver Kanasiro et al., 2008).

9 Uma pesquisadora de populações indígenas, ao saber de nosso trabalho, concluiu: "Então vocês são uns etnólogos urbanos!" Assumimos a classificação: a equipe passou a se autodenominar GEU (Grupo de Etnologia Urbana). 
táticas para inserir-se no espaço urbano - cada um desses temas resultou em relatórios de iniciação científica, artigos, teses e dissertações ${ }^{10}$.

Ademais, o compartilhamento ocorreu não apenas entre antropólogos e membros da equipe pois, além da relação com os etnólogos da Universidade Federal do Amazonas (UFAM), estendeu-se também aos geógrafos orientados pelo professor Jose Aldemir de Oliveira, na época também diretor da Universidade Estadual da Amazônia (UEA), com a pesquisa que se seguiu, com financiamento do Pronex: "Cidades médias da calha do rio Solimões" (Nepecab/UFAM, 2012-2015). E esse contato deu-se não só em conversas nas demoradas viagens em barcos-recreio pelos rios Negro e Solimões ou durante as refeições nos pequenos hotéis nas cidades ao longo desses rios, mas redundou na contínua troca de dados de GPS, relatos, fotos, mapas, croquis...

Os resultados, principalmente as teses e dissertações dos membros do NAU envolvidos - por exigências acadêmicas - tiveram de ser individuais, mas o trabalho foi coletivo e a convivência, intensamente compartilhada: contudo, ainda não tínhamos introduzido o conceito de "etnografia compartilhada"; estava sendo: experienciada. ${ }^{11}$

\section{A pesquisa no Sesc}

A próxima experiência - a pesquisa no Serviço Social do Comércio (Sesc) formalizou esse conceito e sua estratégia de trabalho. Tudo começou com a sugestão da gestora de uma das unidades da instituição, em São Paulo, após ter cursado a disciplina "Práticas culturais no contexto urbano", no Departamento de Antropologia da FFLCH da USP: que tal um pesquisa em moldes etnográficos sobre os frequentadores - suas motivações, reivindicações, comportamentos?

Segundo ela (com toda razão) os habituais meios de investigação, principalmente surveys, deixavam passar valiosas informações que a antropologia com seu método poderia aportar. Assim surgiu "Cultura e lazer: práticas físico-esportivas dos frequentadores do Sesc em São Paulo". Uma pesquisa-piloto

10 Do relatório final saiu uma publicação com o titulo do projeto: Paisagens ameríndias: lugares, circuitos e modos de vida na Amazônia (Amoroso; Mendes, 2013).

11 Os títulos de algumas dessas dissertações e teses estão em Agnello (2013), Chiquetto (2014), Fiori (2018) e Sertã (2018). 
foi realizada na unidade de Santo Amaro, com o objetivo de identificar alguns eixos interpretativos para servirem de guia nas demais unidades - foram sete na capital, uma no litoral e outra na Grande São Paulo, de fevereiro a dezembro de 2015; as do interior, cinco, de janeiro a junho de 2017.12 Todos os dias, da abertura ao fechamento da unidade, ao menos dois dos 11 pesquisadores (mesclando gênero, idade, formação acadêmica, inserção profissional) se faziam presentes em regime de imersão.

Os eixos iniciais obtidos na pesquisa-piloto foram: 1) características da unidade: fluxos, perfil do público, programação e arquitetura; 2) o Sesc na cidade: entornos, circuitos e manchas; 3) instituição e regras; 4) marcadores sociais da diferença: classe, raça, geração, gênero e sexualidade; 5) usos do tempo no Sesc: rotina, trabalho, lazer e tempo livre.

Terminada a pesquisa, esses eixos, retrabalhados nas demais unidades e acrescidos das expressões usadas pelos usuários (estão em itálico), serviram de títulos para os capítulos do relatório final: "Olhe ao seu redor, o que esse Sesc pode lhe oferecer: o Sesc e as cidades"; "Não existe férias sem Sesc: temporalidades e usos ao longo do tempo"; "O que essa menina veio fazer no meio de um monte de velho?: o que é ser criança, jovem e idoso no Sesc”; "O Sesc é meu quintal: relações de pertencimento e acolhimento no Sesc-SP".

No interior: "Tem que entender a cidade: dinâmicas e movimentos entre os municípios do interior paulista e as unidades do Sesc"; "O Sesc é a referência: relações de pertencimento e acolhimento nas unidades do Sesc do interior de São Paulo"; “Ô, usuário!: categorias identitárias e construções de pessoa com base no discurso de frequentadores e funcionários do Sesc"; "O Sesc é um outro mundo: as formas de habitar as unidades do interior de São Paulo".

Alguns achados, um deles flagrado com base na condição de gênero: indo ao banheiro feminino, uma das pesquisadoras observou uma intensa atividade de senhoras mais idosas, vendendo e trocando objetos de tupperware, de uso doméstico; outro exemplo, de usos e contrausos: uma jovem sentada sozinha no alto da arquibancada de uma quadra esportiva, ao ser interpelada

12 Na primeira etapa, no município de São Paulo: Belenzinho, Consolação, Itaquera, Pompeia, Santana, Santo Amaro e Vila Mariana; na Grande São Paulo: Santo André; litoral: Santos; interior: Araraquara. Na segunda etapa, todas no interior do estado: Campinas, Presidente Prudente, São José do Rio Preto, Sorocaba e Taubaté. No total, há 43 unidades do Sesc em todo o estado de São Paulo. 
sobre o que estava fazendo, respondeu: - "Nada!" E ratificou: "Venho aqui fazer um monte de nada!" Exemplos de usos não previstos pela intensa programação oficial do Sesc, não percebidos pelos funcionários, mas sim pelo olhar etnográfico...

O compartilhamento ocorreu também com alguns funcionários da instituição que se agregaram à pesquisa e principalmente com o Centro de Estudos de Cultura Contemporânea (Cedec), encarregado da parte quantitativa: a ideia era sugerir aos sociólogos desse centro, também contratado pelo Sesc, que incluíssem nos questionários algumas questões que surgiram após a pesquisa-piloto na unidade Santo Amaro. Uma das novidades foi o experimento com o aplicativo MaxQDA, para auxiliar na redação dos relatórios finais, seguindo os eixos interpretativos: uma coisa era ler os relatos de campo ao longo da pesquisa, outra, encarar as 2 mil páginas compiladas. Os resultados foram condensados em dois relatórios finais, o da capital com 309 páginas e o do interior com 192 páginas. Alguns capítulos de uma coletânea sobre lazer publicada pelo próprio Sesc divulgaram a pesquisa para um público mais amplo (Magnani; Spaggiari, 2018).

\section{Centros Educacionais Unificados (CEUs/SP)}

Nesse caso o trabalho foi realizado por cinco pesquisadores da equipe "Argonautas - Pesquisa Enográfica". Assim como havia ocorrido com a pesquisa no Sesc, a atividade que realizamos nos CEUs foi solicitada e financiada por uma instituição não acadêmica, reforçando a tendência que, a nosso juízo, deveria aliar a especificidade da instituição e sua demanda - nesse caso, a Secretaria de Educação do Município de São Paulo e seu projeto "CEU, memórias e ação"com o rigor acadêmico.

Nossa participação nesse projeto propunha, como experimento, ampliar o conceito de compartilhamento: em vez de os pesquisadores assumirem a pesquisa e entregarem resultados, dessa vez a proposta era realizar oficinas de formação com professores, gestores, funcionários, alunos e até moradores para que se apropriassem do método etnográfico e assim participassem, a seu modo, junto aos integrantes da equipe dos Argonautas, do trabalho de campo e da elaboração dos relatos. No ano de 2018 foram visitadas dez unidades e no decorrer de 2019/2020 as 36 restantes. 
Como se sabe, a construção dos CEUs foi uma iniciativa da então prefeita Marta Suplicy na gestão 2001-2004 com a entrega das 21 primeiras unidades; de certa forma tinha como antecedente e inspiração a experiência dos Centros Unificados de Educação Pública (Cieps) de Leonel Brizola e Darcy Ribeiro, no Rio de Janeiro. Em São Paulo são atualmente 46 unidades, as demais projetadas ao longo das gestões posteriores à de Marta Suplicy: 24 na de Gilberto Kassab e, na de Fernando Haddad, apenas uma, o CEU Heliópolis, em virtude de cortes orçamentários; estão distribuídas estrategicamente por toda a periferia, atendendo em torno de 120 mil alunos.

Se fosse possível fazer uma relação com a saga de Malinowski (pano de fundo deste texto) poder-se-ia aproximar, metaforicamente, essa localização e o percurso entre elas com as ilhas do arquipélago de Trobriand, ainda que não tenha propriamente o caráter do kula.

Como os Cieps do Rio, cujo projeto arquitetônico teve a marca de Oscar Niemeyer, os CEUs de São Paulo caracterizam-se pela qualidade e funcionalidade da edificação e principalmente pela proposta que ia além da questão escolar convencional: as unidades eram equipadas - além das previsíveis salas de aula - com piscina, quadras poliesportivas, bibliotecas, auditórios para teatro e cinema.

Ademais, situadas em áreas carentes, tinham também o propósito de se aproximar dos moradores: foi justamente para recuperar essa relação que, após a oficina sobre metodologia, aplicamos a técnica da caminhada etnográfica coletiva pelo bairro (cada participante munido de seu caderno de campo), no sentido de reaproximar a instituição do entorno. O mote, "de perto e de dentro/ de longe e de fora", que orienta nossas pesquisas etnográficas, foi transformado em "de perto e de cima", e "de perto e em volta", dada a localização de cada CEU num ponto mais elevado ou de destaque na paisagem.

Assim, essa instituição foi erigida como uma espécie de observador privilegiado de seu entorno, atento às mudanças do bairro, às trajetórias de seus moradores, suas lideranças comunitárias, suas memórias. Terminada a primeira fase, foi empreendida nova rodada pelos 46 CEUs para uma devolutiva com compartilhamento das experiências, registradas nos cadernos de campo dos participantes e transcritas nos seus relatos. Está em preparação um livro com o resultado desse trabalho coletivo, a ser publicado pela Secretaria da Educação do Município de São Paulo. 


\section{Museu do Ipiranga}

Fechado desde 2013 por graves problemas estruturais, o restauro desse edifício, inaugurado em 1895, começou em outubro de 2019 e, com o término das obras previsto para 2022, a inauguração será (espera-se) no Sete de Setembro desse ano. A inusitada questão de um museu universitário, voltado para a pesquisa e também para visitação - destino obrigatório de muitas escolas de ensino médio do interior do estado, por exemplo - estar todo esse tempo fechado colocava novas questões: a diretoria do museu nos contatou para saber de que forma a etnografia poderia colaborar nessa conjuntura. Havia já iniciativas para ocupar o espaço, por meio de contatos com instituições vizinhas do entorno, como o Sesc Ipiranga, com apresentações teatrais de grupos independentes no hall do museu, diante da famosa pintura O grito, autoria de Pedro Américo.

O título do nosso projeto era "Ocupação Museu do Ipiranga: desvelamentos de um experimento etnográfico", financiado pela Fundação Universidade de São Paulo (Fusp). O período de trabalho de campo, com oito pesquisadores novamente combinando gênero, idade, formação acadêmica, da graduação à pós-graduação - durou de outubro de 2018 a julho de 2019, com o acréscimo, nesse mesmo ano, de uma imersão coletiva em campo no dia da comemoração do Sete de Setembro. ${ }^{13}$

A proposta do NAU, conforme explicitada no título, foi inicialmente promover uma "ocupação" de seu espaço, começando com a atividade "Primeiro encontro entre mulheres residentes em ocupações e o Museu do Ipiranga". Eram 29 integrantes de movimentos de ocupações de edifícios abandonados, no centro da cidade e também em áreas em periferia, gerenciados pelo MTST, onde o NAU já havia feito etnografia. A atividade consistiu em uma caminhada etnográfica por dentro do museu - por salas vazias, escadas, desvãos, até o teto de onde se descortinava uma vista panorâmica da mancha toda.

Em seguida, roda de conversa diante da exposição "O morar paulistano", da historiadora Vania Carneiro de Carvalho, com objetos domésticos tradicionais. Os pesquisadores registravam as impressões e os contrastes na fala das

13 Pesquisadores: Fabiano Torres, Jacia Kanarski, Jade Gonçalves, Marciano Kappaun, Patricia Montini, Priscila Cevada, sob consultoria de José Guilherme Cantor Magnani e coordenação de Júlio Cesar Talhari. 
participantes, comparando aqueles objetos com os de seu cotidiano, nas ocupações. Houve compartilhamento da pesquisa também com funcionárias do museu, principalmente do setor educativo, que, na continuação, propuseram também uma outra versão de compartilhamento: "curadorias compartilhadas", a partir da visão de diferentes públicos. Outras propostas foram as batalhas de MCs e competições de poesia, os slams e, finalmente, uma imersão etnográfica no Dia da Independência, em 7 de setembro de 2019.

De uma maneira geral, nesse caso, seguindo com as comparações com os Argonautas, estávamos frente a uma só "aldeia" e, ademais, vazia; então o interesse voltou-se para o entorno, a mancha: o parque, o monumento, a cripta, a praça, e seus variados frequentadores: skatistas, famílias, monarquistas, passeadores com seus pets.

\section{Expedição Vale do Rio Doce: rompimento da barragem de Fundão (MG)}

Essa pesquisa foi realizada a partir da solicitação de uma empresa ${ }^{14}$ para levantar os danos ao patrimônio cultural imaterial em consequência do rompimento da barragem de Fundão em Mariana (MG). Aqui, um dos diferenciais foi a extensão territorial coberta durante quatro meses de trabalho: do município de Mariana até a foz do rio Doce, desembocando no mar, já no estado do Espírito Santo. Mais concretamente, foram percorridos, por oito pesquisadores, 650 quilômetros durante 56 dias de campo, ao longo de 59 localidades em 27 municípios, entre agosto e novembro de 2018. Para completar o levantamento, mais duas viagens específicas em terras indígenas, dos Krenak (Resplendor-MG), Tupiniquim e Guarani (Aracruz-ES) em março e maio de 2019.

Nesse caso, o compartilhamento com discussão sobre os achados, troca de fotos, dados de GPS e mapas estendeu-se no convívio com arqueólogos e arquitetos, estes voltados para os bens de cultura material danificados (sítios arqueológicos, edificações).

No nosso caso, o recorte era o patrimônio imaterial, ou seja, lugares, celebrações, formas de expressão, ofícios, saberes e modos de fazer, segundo a definição do Iphan. Os danos descritos foram classificados como alteração

14 Contrato com Zanettini Arqueologia e Instituto de Tecnologia para o Desenvolvimento (Lactec). 
de práticas culturais, da rede de relações comunitárias, de espaços relacionados a essas práticas e de referência à memória, no acesso a matérias-primas e implementos necessários à produção dos bens culturais; entrevistas mais formais precisavam de assinatura do termo de consentimento.

Uma vez que as informações colhidas em campo fariam parte de um processo a ser acionado pelo Ministério Público, para efeitos de imposição de ressarcimento à empresa causadora do desastre, foi preciso assinar um termo de confidencialidade, de forma que só agora foi permitida sua divulgação (Institutos Lactec, 2020).

Essa questão do ressarcimento evidenciou uma dificuldade adicional, no caso específico do patrimônio imaterial: como valorar uma Festa do Divino que não pode ser mais realizada em razão do desastre? Quais as consequências da interrupção dessa e de outras celebrações, integrantes do modo de vida da população de um bairro rural ou pequena cidade, em razão de rompimento de laços de parentesco, vizinhança, da rede de obrigações, ou da destruição de igrejas ou capelas? E que dizer dos ritos ancestrais indígenas no rio, agora poluído pelos dejetos? Como quantificar e monetizar esse tipo de dano ao patrimônio imaterial, para efeitos de reparação? Como foi argumentado, chegar a alguma conclusão nessas questões exigiria um acercamento ao campo com outros pressupostos, cronograma de trabalho, metodologia.

Assim, o compartilhamento, do ponto de vista das empresas contratantes, acostumadas com números, métricas e pesos, ficou mais difícil em relação com os protocolos e normas éticas da pesquisa antropológica. Até os cadernos de campo teriam de ser disponibilizados... o que foi pronta e devidamente negado.

\section{Desdobramentos e aproximações}

Uma das constantes em Argonautas é a aproximação com a ciência, tal como se pode perceber em inúmeras recomendações do tipo: "como geralmente acontece quando o interesse científico se volta para um campo explorado pela curiosidade de amadores, a etnologia trouxe leis e ordem àquilo que parecia caótico e anômalo" (Malinowski, 1978, p. 23); "a pesquisa de campo realizada em moldes científicos supera em muito quaisquer trabalho de amadores" (Malinowski, 1978, p. 27) e outras, corroboradas neste trecho: 
Em primeiro lugar, é lógico, o pesquisador deve possuir objetivos genuinamente científicos e conhecer os valores e critérios da etnografia moderna. Em segundo lugar, deve o pesquisador assegurar boas condições de trabalho, o que significa, basicamente, viver mesmo entre os nativos, sem depender de outros brancos. Finalmente, deve ele aplicar certos métodos de coleta, manipulação e registro de evidência. (Malinowski, 1978, p. 20).

Esses são os três princípios metodológicos que orientaram seu trabalho e desdobrados num quadro a partir das metáforas: esqueleto, corpo e sangue, espírito, que remetem a uma visão de sociedade como um organismo vivo, bem ao gosto do autor:

\begin{tabular}{|c|c|c|c|}
\hline Metáforas & Objeto & Instrumentos & Objetivo \\
\hline Esqueleto & $\begin{array}{c}\text { A organização da tribo e a } \\
\text { anatomia da sua cultura }\end{array}$ & $\begin{array}{c}\text { Documentação concreta e } \\
\text { estatística por meio de censos, } \\
\text { tabelas, genealogias, gráficos }\end{array}$ & Identificar as leis \\
\hline $\begin{array}{c}\text { Corpo e } \\
\text { sangue }\end{array}$ & $\begin{array}{c}\text { O cotidiano, as atitudes, os } \\
\text { “imponderáveis da vida real” }\end{array}$ & Diário de campo & $\begin{array}{c}\text { Descrever os } \\
\text { comportamentos }\end{array}$ \\
\hline Espírito & $\begin{array}{c}\text { Os modos estereotipados } \\
\text { de pensar: fórmulas mágicas, } \\
\text { provérbios, narrativas típicas }\end{array}$ & $\begin{array}{c}\text { Construção do } \\
\text { corpus inscriptionum }\end{array}$ & $\begin{array}{c}\text { Registrar a men- } \\
\text { talidade nativa }\end{array}$ \\
\hline
\end{tabular}

Malinowski contrapunha a "etnografia moderna" - que para ele significava lançar mão de tabelas, mapas, censos, quadros sinópticos, registro em diários - ao caráter conjetural dos pressupostos das escolas evolucionista e difusionista. Se o estatuto científico da antropologia aproximava o etnógrafo em campo, colhendo seus dados, ao botânico às voltas com sistemas de nomenclatura e classificação dos espécimes observados, ele apontava, contudo, diferenças:

[...] o etnógrafo tem o dever e a responsabilidade de estabelecer todas as leis e regularidades que regem a vida tribal, tudo que é permanente e fixo; apresentar a anatomia da cultura e descrever a constituição social, [...] esses elementos, apesar de cristalizados e permanentes, não se encontram formulados em lugar nenhum. Não há códigos de lei, escritos ou expressos explicitamente; toda a tradição tribal e sua estrutura social inteira estão incorporadas ao mais elusivo dos materiais: o ser humano. (Malinowski, 1978, p. 24). 
Essa preocupação toda tem a ver com a necessidade de outorgar estatuto objetivo à antropologia, segundo a tendência da época sobre a importância que as ciências, principalmente as naturais, começavam a ter. Hoje essa centralidade e suposta objetividade das hard sciences - com base também nas supostas imutáveis leis da natureza - está em discussão, como se pode ver em Ciência em ação de Bruno Latour (1997), entre outros textos e em Isabelle Stengers (1993, 1997), com sua proposição sobre cosmopolítica. ${ }^{15}$ Numa arriscada síntese: os fatos científicos não são descobertos, mas construídos (em laboratórios, com instrumentos, protocolos) e só se apresentam como objetivos quando as polêmicas suscitadas por sua formulação temporariamente se estabilizam nesse meio para, em seguida, serem absorvidos e também manipulados politicamente em círculos mais amplos.

Malinowski, contudo, como também fica claro na citação acima, não obstante a importância que dava à ciência, não abdicava da especificidade do labor etnográfico. Essa busca de regularidades - e não o mero registro de eventos ou relato do fluxo das coisas -, segundo o ângulo de cada olhar, continuou pautando a prática dos etnógrafos. E uma das estratégias para manter essa postura, como tentei mostrar nas experiências anteriores, foi a ideia de compartilhamento (e confronto) de olhares entre os pesquisadores a partir de suas diferenças de gênero, formação, idade, etc. e dos relatos individuais a partir das observações registradas nos seus cadernos de campo. Dessa forma evita-se a acusação de subjetividade do olhar do antropólogo, ou de ser mero "porta-voz dos nativos", mas sem a necessidade de apelar para a suposta objetividade atribuída às hard sciencies. ${ }^{16}$

Esse compartilhamento do método etnográfico também se dá com outros atores não necessariamente antropólogos, respeitando e incorporando as especificidades de seus olhares, seja como sujeitos da pesquisa em curso ou especialistas de outras áreas. Tal postura vem despertando interesse por parte das hard: recentemente o LabNAU foi procurado pelo Instituto de Pesquisas

15 Um oportuno relato sobre essa questão: "Dossiê de Antropologia: Entreviver - desafios cosmopolíticos contemporâneos" (Revista do Instituto de Estudos Brasileiros, 2018, p. 24-360).

16 Outra linha de revisão crítica da proposta malinowskiana, dessa vez sobre sua concepção de trabalho de campo, pode ser vista em Giumbelli (2002). 
Tecnológicas do Estado de São Paulo (IPT) ${ }^{17}$ para uma parceria num projeto que seus técnicos desenvolvem sobre autoconstrução em uma favela da cidade: levar em conta o saber dos moradores é fundamental, assim como abrir espaço para que estes entrem em contato com as normas, procedimentos e instrumentais de sua prática; sem dúvida, mais uma forma de compartilhamento.

Outro aspecto que permite uma aproximação - e contraste - entre as pesquisas desenvolvidas no LabNAU e as recomendações de Malinowski em Argonautas é a questão da totalidade. Em vez da costumeira ideia, vigente em sua época, de que os "selvagens constituíam povos sem lei e sem rei" - ou seja, vivendo na ausência de regras formais, Malinowski mostrou que o cotidiano, o modo de vida, a economia, o parentesco, a religião, etc. entre os trobriandeses apresentavam regularidades que tinham como base a noção de totalidade; claro, não estava nada escrito, era preciso, como foi dito mais acima, reconstruí-la a "partir do mais elusivo dos materiais: o ser humano". Para isso, no tempo e nas condições de que dispõe em campo, o etnógrafo lançou mão de atalhos: as instituições, como o kula, por exemplo, ao mesmo tempo fato econômico, de diplomacia, religioso... e que em nada ficavam a dever a instituições britânicas similares.

O etnógrafo às voltas com a realidade das cidades contemporâneas, contudo, enfrenta outros desafios. Claro, algumas disciplinas tomam a cidade como uma totalidade com fronteiras bem delimitadas: o município de São Paulo, a região metropolitana, a Grande São Paulo, etc. para efeitos de gestão, como os planos diretores, por exemplo. A essa perspectiva apliquei a denominação "de longe e de fora", para contrastar com a "de perto e de dentro", própria da aproximação etnográfica. Nessa linha, a cidade como totalidade não é um ponto de partida, mas - ao longo e ao cabo de sucessivas aproximações - ponto de chegada, ou, melhor dizendo, horizonte de chegada.

Em artigo anterior, publicado há alguns anos nesta revista, "Etnografia como prática e experiência", afirmava:

Partir das regularidades, dos padrões e não das dissonâncias ou desencontros como condição da pesquisa supõe uma contrapartida no plano teórico: alguma

17 Esse instituto foi fundado em 1899 como Gabinete de Resistência dos Materiais da Escola Politécnica da Universidade de São Paulo. 
ideia de totalidade como pressuposto. Não se trata, evidentemente, daquela totalidade que evoca um todo orgânico, funcional, sem conflitos e tampouco se trata de uma totalidade que coincide, no caso da cidade, com os seus limites político-administrativos. No entanto, renunciar a esses tipos de totalidade não significa embarcar no extremo oposto: um mergulho na fragmentação pois, se não se pode delimitar uma única ordem, isso não significa que não haja nenhuma. A questão da totalidade coloca-se, dessa maneira, em múltiplos planos e escalas. (Magnani, 2009, p. 137).

Exemplificava, nesse artigo, o caso de uma etnografia sobre a presença dos surdos na cidade de São Paulo, compartilhada com integrantes do Departamento de Linguística da USP. Diferentemente da visão inadequada sobre eles como deficientes, interessando apenas a fonoaudiólogos e invisíveis na paisagem da cidade, a pesquisa mostrou sua inserção - seus pedaços, manchas trajetos e circuito; enfim, a cidade dos surdos é uma, é outra.

Finalizo este item com uma relação que costumo fazer entre a perspectiva malinowskiana - descrita naquele seu passeio matinal pela aldeia, em que se descortinava diante de si o cotidiano dos moradores - e a situação do antropólogo urbano, imerso na metrópole contemporânea:

No meu passeio matinal pela aldeia, podia observar detalhes íntimos da vida familiar - os nativos fazendo sua toalete, cozinhando, comendo; podia observar os preparativos para os trabalhos do dia, as pessoas saindo para realizar suas tarefas; grupos de homens e mulheres ocupados em trabalhos de manufatura. Brigas, brincadeiras, cenas de família, incidentes geralmente triviais, às vezes dramáticos, mas sempre significativos, formavam a atmosfera da minha vida diária, tanto quanto a da deles. (Malinowski, 1978, p. 21).

Evans-Pritchard (1978, p. 20) complementa: "Da porta da minha barraca podia ver o que acontecia no acampamento ou aldeia e todo o tempo era gasto na companhia dos Nuer." Se esta passagem de Os Nuer: uma descrição do modo de subsistência e das instituições políticas de um povo nilota constitui outra imagem da pesquisa de campo, nada mais distante, então, das condições de trabalho de um antropólogo às voltas com questões e problemas das modernas sociedades urbano-industriais, cujo campo é a cidade: da janela de sua quitinete o que 
vislumbra não é a vida social em sua totalidade, mas, muitas vezes, a empena cega do edifício em frente... E mesmo que conviva mais intensamente com o grupo que está estudando, nem sempre gasta todo o tempo em sua companhia (Magnani, 1996, p. 19-20).

Como sair do impasse? Denominei uma dessas saídas de "a tentação da aldeia": ou seja, o antropólogo considerar a cidade como uma espécie de aldeia que cresceu demais, ultrapassou os limites e nesse caso não haveria como escapar de generalidades; ou então ficar circunscrito (e se especializar em) aos limites de seu recorte de pesquisa - tal ou qual terreiro de candomblé, uma festa na periferia, um coletivo de jovens, uma associação de bairro, uma forma de lazer... É a (falsa ou fácil) escolha entre a perspectiva "de perto e de dentro" e a "de fora e de longe". Na verdade, não se opõem, mas se complementam: essa suposta escolha na verdade não é um impasse, e sim um desafio e até uma hipótese: não seria justamente esse olhar, "de perto e de dentro", a contribuição específica da etnografia, em seus recortes de campo para avançar em direção a uma perspectiva mais ampla, em diálogo com outras abordagens, mais macro?

\section{Conclusão}

O artigo "Etnografia como prática e experiência", publicado nesta mesma revista, começava citando uma matéria da Folha de S. Paulo na qual, entrevistado pelo repórter sobre o comportamento atual de consumidores, o diretor de uma empresa de consultoria afirmava:

Muitas [empresas] estão incluindo antropólogos em seus quadros e investindo em pesquisas etnográficas, espécie de estágio em que executivos convivem com famílias de baixa renda dentro de suas residências observando seu cotidiano. (Magnani, 2009, p. 130).

Se essa insólita definição de etnografia - "espécie de estágio em favela", que era como aparecia na epígrafe da citada matéria do jornal - mostra um (in) discutível prestígio da etnografia para além do âmbito da academia, não se pode ignorar seus usos em outros campos, uns afins à antropologia, outros nem 
tanto. No presente texto, agora, segui uma determinada linha de argumentação que teve como base a trajetória de um grupo de pesquisa no Departamento de Antropologia da FFLCH da USP, o LabNAU: suas escolhas, sua metodologia, seu reconhecimento do legado de Bronislaw Malinowski. No entanto, só nesse departamento há atualmente 14 grupos, cada qual com seu recorte, sua bibliografia, seus projetos e, por conseguinte, estratégias de pesquisa. ${ }^{18}$

Pense-se, agora, em outros departamentos das demais universidades brasileiras... haveria um débito em comum com o legado de Malinowski? De que forma? Um ponto certamente compartilhado é que não se vai a campo na condição de tabula rasa, mas sim munido com informações de estudos anteriores - não na linha de dar suposto estatuto "científico" ao trabalho, como se poderia concluir a partir de uma leitura descontextualizada de alguma asserções em Argonautas, aliás posteriormente bastante criticadas, como foi apontado mais acima (nota n. 1), mas com base em dados já existentes; daí a distinção que faço entre etnografia como "prática e experiência", no artigo em Horizontes Antropológicos já citado. E que dizer na conjuntura atual, com as tentativas de etnografia online, inimaginável nos tempos de Bronislaw Malinowski?

Pode parecer meio forçada essa aproximação das pesquisas aqui descritas com a clássica etnografia proposta em Argonautas. Mas é inegável, apesar das diferenças de contexto e época, reconhecer a centralidade da pesquisa de campo, o contato direto com o cotidiano e modo de vida dos interlocutores por meio da escuta, do registro e do compartilhamento. E agora a pandemia, uma conjuntura inesperada e de alcance global, põe em risco justamente essa característica marcante da prática etnográfica; como fazer campo sem esse contato, com base em dados colhidos em redes sociais?

Um dos grupos do laboratório do Núcleo de Antropologia Urbana, o, CyberNAU ${ }^{19}$ está também voltado para a discussão desse tema com base em

18 CANIBAL (Grupo de Antropologia do Caribe Global); CERNe (Estudos de Religiosidades Contemporâneas e das Culturas Negras); COLETIVO ASA (Grupo de Pesquisa em Artes, Saberes e Antropologia); ETNO-HISTÓRIA (Antropologia e História); GEAC (Antropologia da Cidade) GRAVI (Antropologia Visual); HYBRIS (Relações de Poder, Conflitos, Socialidades); NADIR (Antropologia do Direito); NAPEDRA (Antropologia, Performance e Drama); NUMAS (Marcadores Sociais da Diferença); PAM (Pesquisas em Antropologia Musical). Laboratórios de Pesquisa: LISA (Laboratório de Imagem e Som em Antropologia) NAU (Laboratório do Núcleo de Antropologia Urbana); Núcleo de Apoio à Pesquisa (NAP); CEstA (Centro de Estudos Ameríndios).

19 Este grupo é coordenado pela mestranda Fabiana Botton. 
bibliografia e pesquisas em andamento em diferentes centros acadêmicos: entre os pesquisadores brasileiros, além do trabalho de Theophilos Rifiotis, Jean Segata, Juciano Lacerda e de Maria Elisa Máximo (Rifiotis et al., 2010), podem ser mencionados os trabalhos pioneiros de Adriana Dias (2007), que fez uma etnografia do neonazismo na internet, o de Adla Bourdoukan (2007), que pesquisou os góticos na internet, o de Patrícia Ferreira e Silva (2014), que pesquisou a presença das religiões afro-brasileiras no ciberespaço, e ainda o de Mário José Lopes Guimarães Júnior (2004) sobre os avatares e o ciberespaço. Podem também ser citados os textos de Christine Hine (2001), Virtual ethnography, e o de Daniel Miller e Don Slater (2004), "Etnografia on e off-line: cybercafés em Trinidad”, este último, como o de Mário José Lopes Guimarães, publicado em Horizontes Antropológicos.

Certamente a pandemia tornou mais complexo esse quadro: pesquisadores em todo o mundo se viram em meio a dilemas sobre como dar continuidade a suas pesquisas e como conduzir seus trabalhos de campo online. No entanto, não se trata apenas de uma tentativa de ajuste a essa nova conjuntura ou de buscar formas de contornar as dificuldades em se fazer etnografia nos moldes habituais; trata-se de um verdadeiro desafio, certamente diferente, mas que nada fica a dever aos encontrados pelos etnógrafos ao longo da história da antropologia. Ademais, as ferramentas digitais podem ser úteis para que se repense a etnografia e a dimensão do campo, não apenas do campo virtual, mas também em novas formas de conexão com os interlocutores.

Voltando ao âmbito da família de categorias usadas no LabNAU - haveria um pedaço virtual? As redes sociais constituem circuitos? Quando se sai de um grupo de debates, uma live ou reunião de Zoom ou Meet, e vai-se para outro, trata-se de trajeto? Situação inusitada, mas quando se compara com a iniciativa de, em plena Primeira Guerra Mundial, aventurar-se desde a Europa até um minúsculo arquipélago na Melanésia e, lá chegando, mesmo sem ainda conhecer a língua "iniciar imediatamente seu trabalho etnográfico", após o navio afastar-se até desaparecer no horizonte, não parece que o presente desafio seja muito maior. 


\section{Referências}

AGNELLO, J. Saterização da cidade: identidade, multi-localidade e cultura entre aldeias e cidades habitadas pelos Sateré-Mawé na Amazônia. 2013. Tese (Doutorado em Antropologia Social) - Faculdade de Filosofia, Letras e Ciências Humanas, Universidade de São Paulo, São Paulo, 2013.

AMOROSO, M.; MENDES, G. (org.). Paisagens ameríndias: lugares, circuitos e modos de vida na Amazônia. São Paulo: Terceiro Nome, 2013.

BOAS, F. Handbook of American Indian Languages. Washington: Governement Printing Office, 1922.

BOURDOUKAN, A. Y. Carpe noctem - góticos na internet. In: MAGNANI, J. G.; MANTESE, B. (org.). Jovens na metrópole: etnografias de circuitos de lazer, encontro e sociabilidade. São Paulo: Terceiro Nome, 2007. p. 67-81.

CHIQUETTO, R. A cidade do futebol: etnografia sobre a prática futebolística na metrópole manauara. 2014. Dissertação (Mestrado em Antropologia Social) - Faculdade de Filosofia, Letras e Ciências Humanas, Universidade de São Paulo, São Paulo, 2014.

CLIFFORD, J. A experiência etnográfica: antropologia e literatura no século XX. Organização e revisão técnica de José Reginaldo Santos Gonçalves. Rio de Janeiro: Editora UFRJ, 1998.

CONRAD, J. Coração das trevas. São Paulo: Brasiliense, 1984.

DIAS, A. A. M. Os anacronautas do teutonismo virtual: uma etnografia do neonazismo na internet. 2007. Dissertação (Mestrado em Antropologia Social) - Instituto de Filosofia e Ciências Humanas, Universidade Estadual de Campinas, Campinas, 2007. Disponível em: http://www.repositorio.unicamp.br/handle/REPOSIP/279037. Acesso em: 20 jan. 2021.

DURHAM, E. Malinowski (1884-1942): vida e obra. In: MALINOWSKI, B. Argonautas do Pacífico Ocidental: um relato do empreendimento e da aventura dos nativos nos arquipélagos da Nova Guiné melanésia. São Paulo: Abril Cultural, 1978a. p. v-xxiv. (Coleção Os Pensadores).

DURHAM, E. A reconstituição da realidade. São Paulo: Ática, 1978b.

DURKHEIM, E. Les formes élémentaires de la vie religieuse: le sistème totémique en Australie. Paris: Alcan, 1912.

EVANS-PRITCHARD, E. E. Os Nuer: uma descrição do modo de subsistência e das instituições políticas de um povo nilota. São Paulo: Perspectiva, 1978. 
EXPEDIÇÃO São Paulo 450 Anos: uma viagem por dentro da metrópole. Direção: Lucila Carvalho Junqueira Meirelles e Sérgio Roizenblit. São Paulo: Prefeitura do Município de São Paulo: Petrobras, 2004. 1 DVD/4, color. (52 min).

FIORI, A. L. Como se formam índios acadêmicos?: um estudo sobre trânsitos de cotidianos e saberes entre os discentes dos Cursos de Pedagogia Intercultural da Universidade Estadual do Amazonas. 2018. Tese (Doutorado em Antropologia Social) - Faculdade de Filosofia, Letras e Ciências Humanas, Universidade de São Paulo, São Paulo, 2018.

FREUD, S. Totem und Tabu: einige Übereinstimmungen im Seelenleben der Wilden und der Neurotiker. Leipzig: Hugo Heller und Cie., 1913.

GIUMBELLI, E. Para além do "trabalho de campo": reflexões supostamente malinowskianas. Revista Brasileira de Ciências Sociais, São Paulo, v. 17, n. 48, fev. 2002. DOI: https://doi.org/10.1590/S0102-69092002000100007.

GUIMARÃES JR., M. L. De pés descalços no ciberespaço: tecnologia e cultura no cotidiano de um grupo social on-line. Horizontes Antropológicos, Porto Alegre, ano 10, n. 21, p. 123-154, jan./jun. 2004.

HINE, C. Virtual ethnography. London: Sage, 2001.

INSTITUTOS LACTEC. Diagnóstico socioambiental dos danos decorrentes do rompimento da Barragem de Fundão na bacia do rio Doce e região costeira adjacente: tomo V - patrimônio cultural - bens imateriais. Curitiba: Lactec, 2020. Disponível em: http://www.mpf.mp.br/grandes-casos/caso-samarco/documentos/relatorios-lactec/ tomo-v-patrimonio-cultural-bens-imateriais.pdf. Acesso em: 20 jan. 2021.

KANASIRO, A. et al. Relatório Etnografia da Ocupação. São Paulo: NAU/USP, 2008.

LATOUR, B. Ciência em ação. São Paulo: Editora Unesp, 1997.

LOWIE, R. Indians of the plains. New York: McGraw-Hill Book Company, 1954.

MAGNANI, J. G. C. O velho (e bom) caderno de campo. Sexta Feira, São Paulo, n. 1, p. 8-11, maio 1977.

MAGNANI, J. G. C. Quando o campo é a cidade: fazendo antropologia na metrópole. In: MAGNANI, J. G. C.; TORRES, L. de L. (org.). Na metrópole: textos de antropologia urbana. São Paulo: Edusp, 1996. p. 1-24.

MAGNANI, J. G. C. Etnografia como prática e experiência. Horizontes Antropológicos, Porto Alegre, ano 15, n. 32, p. 129-156, jul./dez. 2009.

MAGNANI, J. G. C. Da periferia ao centro: trajetórias de pesquisa em antropologia urbana. São Paulo: Terceiro Nome, 2012. 
MAGNANI, J. G. C. et al. (coord.). Expedição São Paulo 450 anos: uma viagem por dentro da metrópole. São Paulo: Secretaria Municipal da Cultura, 2004.

MAGNANI, J. G. C.; SPAGGIARI, E. (org.). Lazer de perto e de dentro: uma abordagem antropológica. São Paulo: Edições SESC São Paulo, 2018.

MALINOWSKI, B. The family among the Australian aborigines: a sociological study. London: University of London Press, 1913.

MALINOWSKI, B. Argonauts of the Western Pacific: an account of native enterprise and adventure in the archipelagoes of Melanesian New Guinea. London: Routledge \& Kegan Paul, 1922.

MALINOWSKI, B. Argonautas do Pacífico Ocidental: um relato do empreendimento e da aventura dos nativos nos arquipélagos da Nova Guiné melanésia. São Paulo: Abril Cultural, 1978. (Coleção Os Pensadores).

MALINOWSKI, B. A diary in the strict sense of the term. Stanford: Stanford University Press, 1989.

MARCUS, G. Etnografía en/del sistema mundo - el surgimiento de la etnografía multilocal. Alteridades, [s. l.], v. 11, n. 22, p. 111-127, 2001.

MILLER, D.; SLATER, D. Etnografia on e off line: cybercafés em Trinidad. Horizontes Antropológicos, Porto Alegre, ano 10, n. 21, p. 41-65, jan./jun. 2004.

RADCLIFFE-BROWN, A. R. The Andaman islanders: a study in social anthropology. Cambridge: Cambridge University Press, 1922.

REVISTA DO INSTITUTO DE ESTUDOS BRASILEIROS. São Paulo, n. 69, 2018. Disponível em: https://www.revistas.usp.br/rieb/issue/view/10637. Acesso em: 20 jan. 2021.

RIFIOTIS, T. et al. Antropologia no ciberespaço. Florianópolis: Editora da UFSC, 2010.

RIVERS W. H. R. The Todas. London: McMillan and Co. Limited, 1906.

SELIGMAN C. G. The Melanesians of British New Guinea. Cambridge: Cambridge University Press, 1910.

SERTÃ, A. L. Seguindo sementes: circuitos e trajetos de mulheres Sateré-Mawé entre cidade e aldeia. São Paulo: Terceiro Nome: Gramma, 2018.

SILVA, P. F. e. Axé on-line: a presença das religiões afro-brasileiras no ciberespaço. 2014. Dissertação (Mestrado em Antropologia Social) - Faculdade de Filosofia, Letras e Ciências Humanas, Universidade de São Paulo, São Paulo, 2014. Disponível em: https://www.teses. usp.br/teses/disponiveis/8/8134/tde-02072014-090834/pt-br.php. Acesso em: 20 jan. 2021. 
SPENCER, B.; GUILLEN, J. The native tribes of Central Australia. London: Macmillan, 1899.

STENGERS, I. L’invention des sciences modernes. Paris: La Découverte, 1993.

STENGERS, I. Sciences et pouvoir. Paris: La Découverte, 1997.

THORNTON, R. Narrative ethnography in Africa, 1850-1920: the creation and capture of an appropriate domain for anthropology. Man, [s. l.], v. 18, n. 3, p. 502-518, 1983.

Recebido: 26/01/2021 Aceito:23/02/2021 | Received:1/26/2021 Accepted:2/23/2021 